\title{
PARTICULARIDADES DEL CAPITALISMO PERIFÉRICO BRASILEÑO Y SUS RECIENTES OLEADAS DE NEOLIBERALIZACIÓN (1995-2018)*
}

\author{
Recibido: 18 de junio de 2018 - Aprobado: 07 de noviembre de 2018 \\ https://doi.org/10.22395/seec.v22n50a2
}

\author{
Carlos Antônio Brandão* \\ Marcos Barcellos De Souza ${ }^{* * *}$
}

\section{RESUMEN}

Este trabajo tiene por objetivo discutir las interpretaciones que analizan y comparan los diferentes enfoques del sistema capitalista en el siglo XXI haciendo énfasis en el caso específico del capitalismo periférico. Se defiende la existencia de un potente patrimonio académico histórico estructuralista latinoamericano que debe ser rescatado y reactualizado en el contexto de las oleadas contemporáneas del neoliberalismo económico sucedidas durante el siglo XXI. Finalmente, se discuten las principales particularidades de las economías subdesarrolladas y dependientes en la periferia del sistema, destacando el abigarrado capitalismo de Brasil en el periodo reciente.

\section{PALABRAS CLAVE}

Capitalismo; periferia; teorías del desarrollo; subdesarrollo; América Latina; Brasil.

\section{CLASIFICACIÓN JEL}

O10, O20, O54

\section{CONTENIDO}

Introducción; 1. Analizando y comparando los diversos capitalismos en el siglo XXI; 2. El patrimonio académico histórico-estructuralista latinoamericano y las oleadas de neoliberalización en el siglo XXI; 3. Particularidades del capitalismo periférico de Brasil en el periodo reciente: reflexiones inspiradas en el pensamiento crítico latinoamericano; 4 . El proceso de neoliberalización y su carácter cíclico: pensando su singularidad en el Brasil contemporáneo; 5. Conclusiones; Bibliografía.

\footnotetext{
Este artículo es producto de reflexiones de los autores inspiradas por sus líneas de investigación convergentes en los temas de la economía regional y urbana y geografía económica en el ámbito de la Red del Desarrollo Socio-Económico-Espacial Latinoamericano (Redseela.com).

* Economista, Universidade Federal de Uberlândia, MG, Brasil. Maestría en Economía, Universidade Federal de Minas Gerais, Belo Horizonte, MG, Brasil. Doctor en Ciencias Económicas, Universidade Estadual de Campinas, Campinas, SP, Brasil. Profesor titular de la Universidade Federal do Rio de Janeiro, Río de Janeiro, Brasil. Correo electrónico: brandaoufrj@gmail.com.

... Economista, Universidade Federal do Rio de Janeiro, Río de Janeiro, Brasil. Maestría en Desarrollo Económico, Universidade Estadual de Campinas, Campinas, SP, Brasil. Doctor en Desarrollo Económico, Universidade Estadual de Campinas, Campinas, SP, Brasil. Profesor Adjunto de la Universidade Federal do ABC, São Bernardo do Campo, Brasil. Correo electrónico: marcos.barcellos@ufabc.edu.br
} 


\title{
PARTICULARITIES OF THE BRAZILIAN PERIPHERAL CAPITALISM AND ITS RECENT NEOLIBERALIZATION WAVES (1995-2018)
}

\begin{abstract}
This work aims at discussing the interpretations that analyze and compare the different approaches of the capitalist system in the 21 st century by emphasizing the specific case of peripheral capitalism. We defend the existence of a robust Latin American historical-structuralist academic heritage that must be rescued and reupdated in the context of contemporary waves of economic neoliberalism that occurred during the 21 st century. Finally, the main particularities of underdeveloped and dependent economies on the periphery of the system are discussed, highlighting Brazil's mixed capitalism in the recent period.
\end{abstract}

\section{KEYWORDS}

Capitalism; periphery; development theories; underdevelopment; Latin America; Brazil.

\section{JEL CLASSIFICATION}

O10, O20, O54

\section{CONTENT}

Introduction; 1. Analyzing and comparing the various capitalisms in the 21 st century; 2. Latin American historical-structuralist academic heritage and waves of neoliberalization in the 21 st century; 3. Particularities of Brazil's peripheral capitalism in the recent period: reflections inspired by Latin American critical thinking; 4. The process of neoliberalization and its cyclical character: thinking of its uniqueness in contemporary Brazil; 5. Conclusions; Bibliography.

\section{PARTICULARIDADES DO CAPITALISMO PERIFÉRICO BRASILEIRO E SUAS RECENTES ONDAS DE NEOLIBERALIZAÇÃO (1995-2018)}

\section{RESUMO}

Este trabalho tem por objetivo discutir as interpretações que analisam e comparam as diferentes abordagens do sistema capitalista no século XXI com ênfase no caso específico do capitalismo periférico. Defende-se a existência de um potente patrimônio acadêmico histórico estruturalista latino-americano que deve ser resgatado e reatualizado no contexto das ondas contemporâneas do neoliberalismo econômico sucedidas durante o século XXI. Finalmente, são discutidas as principais particularidades das economias subdesenvolvidas e dependentes na periferia do sistema, com destaque para a multiplicidade do capitalismo do Brasil no período recente.

\section{PALAVRAS-CHAVE}

Capitalismo; periferia; teorias do desenvolvimento; subdesenvolvimento; América Latina; Brasil.

\section{CLASSIFICAÇÃO JEL}

010, 020, 054

\section{CONTEÚDO}

Introdução; 1. Analisando e comparando os diversos capitalismos no século XXI; 2. O patrimônio acadêmico histórico-estruturalista latino-americano e as ondas de neoliberalização no século XXI; 3. Particularidades do capitalismo periférico do Brasil no período recente: reflexões inspiradas no pensamento crítico latino-americano; 4. O processo de neoliberalização e seu carácter cíclico: pensando sua singularidade no Brasil contemporâneo; 5. Conclusões; Bibliografia. 


\section{INTRODUCCIÓN}

Los estudios que abordan la diversidad de los enfoques del capitalismo en el tiempo y que resaltan la necesidad de realizar investigaciones de tipo comparativo ocupan hoy importantes proyectos teóricos de la academia mundial.

En el continente latinoamericano, desde la década de 1950, ya existía una sólida acumulación de reflexiones acerca del proceso desigual del desarrollo resultado del atraso de las estructuras que se reproducen a lo largo del tiempo y del espacio. En los países centrales las corrientes teóricas principales siempre practicaron una visión unilateral y mecánica de convergencia inexorable rumbo a una forma superior de organización sociomercantil.

En el inicio del siglo XX, a partir del cúmulo de reflexiones sobre la crisis, y después de 1970, con las transformaciones del capitalismo, se crea una amplia y heterogénea literatura que discute las variedades de capitalismos (VC) para combatir la visión conservadora mencionada en el párrafo anterior. La agenda de investigación bajo la rúbrica de VC se caracterizó, a lo largo de los años, por un considerable eclecticismo que contenía diversas vertientes, el proceso se consolida con la publicación del libro de Hall y Soskice (2001).

El abordaje de las VC, muchas veces olvida el análisis de las instituciones, de las estructuras esenciales para el entendimiento de las manifestaciones concretas y contradictorias del capitalismo. En ese sentido, no se analizan en debida forma el Estado, la sociedad, la representación política, el espacio, el orden competitivo internacional, las coaliciones de negocios y las formas extraeconómicas, que deberían recibir una atención más adecuada.

Este trabajo tiene por objetivo contribuir al entendimiento de la diversidad de las situaciones concretas de las economías subdesarrolladas de América Latina, buscando contribuir con una apropiación teórica más adecuada. A partir del método histórico estructural, se analiza el caso del capitalismo ocurrido en Brasil, poniendo en cuestión las recientes y complejas oleadas de neoliberalización.

Después de la introducción, este trabajo se estructura del siguiente modo: en una primera sección se analiza la literatura especializada que afirma la diversidad y la necesidad de realización de estudios comparativos de las variadas experiencias del capitalismo. En seguida se examina el patrimonio académico histórico-estructuralista latinoamericano en el contexto de las oleadas de neoliberalización en el siglo XXI. Finalmente, se abordan las principales particularidades del capitalismo periférico de Brasil en el periodo reciente y se procede a las consideraciones finales. 


\section{ANALIZANDO Y COMPARANDO LOS DIVERSOS ENFOQUES DEL CAPITALISMO EN EL SIGLO XXI}

La literatura internacional hegemónica ha propugnado, inmediatamente después de la Segunda Guerra Mundial, un sentido implacable de unificación y convergencia del sistema capitalista, rumbo a una especie de meta de tipo ideal de experiencia capitalista monocultural anglo-americano. Ese modelo canónico debería pautar los ajustes necesarios, realizar las correcciones de desvíos y adecuar las instituciones de aquellos países que estaban siguiendo equivocadamente otras vías alternativas, como por ejemplo las desarrollistas populistas.

Así, se defendía la existencia de una tendencia ineludible de convergencia para un modelo óptimo de capitalismo liberal, negando la realidad, que confirma cotidianamente la diversidad de estructuras institucionales y la pluralidad, la heterogeneidad y la divergencia de formas y modos de organización social.

El ahora ya clásico libro editado por Hall y Soskice (2001), al analizar la empresa como institución central de la economía capitalista, puso todo el énfasis en su microcomportamiento estratégico, y consideró su inmersión en un ambiente institucional con incentivos y restricciones en determinados dominios (sistemas financieros y gobernanza corporativa; relaciones industriales; sistemas de educación y entrenamiento; sistema de gobernanza entre compañías y relaciones con sus empleados). Según ellos, a través de sus relaciones con esos cinco dominios, las empresas necesitan resolver problemas de coordinación cruciales en lo que se refiere a sus competencias específicas.

Las preocupaciones por la gobernanza corporativa y la competitividad nacional resultantes del comportamiento estratégico de las empresas inmersas en una matriz de relaciones macroinstitucionales, que presentan coherencia, unidad y lógica peculiares, forman la base de lo que vino a llamarse abordaje mainstream de las VC (Coates, 2005). Hall y Soskice (2001) dejaron clara la distinción entre economías liberales de mercado y economías coordinadas de mercado (ELM-ECM), dos tipos ideales para analizar las diversidades.

Muchas corrientes de pensamiento desarrollaron innumerables diálogos y críticas al abordaje mainstream de la VC. Solo para recordar algunas de las más críticas, mencionamos los sistemas sociales de producción (SSP) (Hollingsworth y Boyer, 1997), en la escuela de la regulación francesa (ERF) (Boyer, 2005) y en las variaciones del capitalismo abigarrado (Peck y Theodore, 2007). 
No hay espacio aquí para dialogar con más detalle con las corrientes de pensamiento mencionadas, pero es bueno recordar que ellas son prismas alternativos de abordaje de las diversidades de capitalismos. Aunque las diferentes vertientes puedan destacar elementos importantes para el entendimiento de las diversidades, la literatura que investiga las variedades no debe ignorar las condiciones para la reproducción del propio capitalismo.

Una parcela de las interpretaciones de las VC y de capitalismos comparativos descuidan las relaciones entre centro y periferia, mientras que otras lo hacen descuidando las dinámicas endógenas y contradictorias de las estructuras (productivas, ocupacionales, de riqueza, entre otras). Presentan así serias limitaciones para entender la diversidad espaciotemporal, estatal, y escalar de las situaciones concretas de las economías subdesarrolladas, dependientes en la periferia, como las de la América Latina.

En ese artículo se busca conferir cierto privilegio analítico a las interpretaciones que destacan las luchas y contradicciones en el proceso de reproducción de las estructuras capitalistas. Las interpretaciones que se insertan en ese grupo, investigan procesos como la acumulación de capital, las luchas de clase, la autonomía relativa del Estado en sus relaciones con la economía y la sociedad y la producción del desarrollo desigual.

El pensamiento crítico histórico estructural desarrollado en América Latina puede ayudar en ese debate sobre diversidad de experiencias capitalistas y en la necesidad de asumir definitivamente que no existe un modelo canónico a seguir en el proceso de desarrollo, sino que existe una pluralidad de vías y trayectorias históricas posibles en el curso del tiempo-espacio del proceso de desarrollo.

\section{EL PATRIMONIO ACADÉMICO HISTÓRICO-ESTRUTURALISTA LATINOAMERICANO Y LAS OLEADAS DE NEOLIBERALIZACIÓN EN EL SIGLO XXI}

América Latina concibió y acumuló, por más de medio siglo, desde el fin de la década de 1940, un inédito patrimonio académico (piénsese en la Comisión Económica para América Latina -Cepal-y Escuela de la Dependencia) para pensar las especificidades del proceso de desarrollado en la condición periférica (Prebisch, 1949, 1981; Furtado, 1961, 1970; Pinto, 1970, 1976; Tavares, 1981).

Desafortunadamente la riqueza, la originalidad y la complejidad del pensamiento crítico de las ciencias sociales desarrollado en este continente no tuvieron la debida divulgación, visibilidad e influencia en el ambiente académico mundial. 
Lo que estaba en el centro del programa de esta elaboración teórica era un proyecto político basado en la concientización y en la búsqueda de la creación de instrumentos para engendrar rupturas en relación con los mecanismos asimétricos del intercambio desigual; con las relaciones centro-periferia, buscando enfrentar las heterogeneidades estructurales en una construcción deliberada de autonomía en un ambiente hostil. Es decir, en un contexto periférico singular, en la mayor porción territorial del mundo, que reúne y pone en convivencia contradictoria las mayores disparidades entre el retraso y el desarrollo de las fuerzas productivas capitalistas. Por ejemplo, el caso de Brasil es revelador, y simultáneamente extremo en esos contrastes y en esas contradicciones: el octavo sistema de fuerzas productivas del capitalismo mundial, combinando con un país que ocupa el puesto 156 en las mediciones de la renta más desigual.

La escuela latinoamericana de pensamiento crítico, histórico y estructural contribuyó en arrojar luz sobre las limitaciones, negligencias y parcialidades de los enfoques desarrollados en los países centrales, al explicar los procesos y trayectorias particulares que han tenido lugar en los espacios nacionales periféricos. Su problemática planteada fue la existencia de un núcleo de acumulación sin el centro de dinamización productivo, innovador y financiero endógeno. Tavares (1981, p. 21) se concentra en el avance desigual, y en el periódico bloqueo de las fuerzas productivas capitalistas como un fenómeno común a todas las economías atrasadas, puesto que "el sector de bienes de capital no tiene dimensiones ni base técnica adecuadas para responder a los requerimientos endógenos de la nueva etapa de industrialización", lo que induce a periódicas desproporciones sectoriales y frecuentes discontinuidades del ciclo de expansión. En suma, el proceso de expansión de la industrialización tendría, según Fajnzylber (1983), una naturaleza siempre trunca.

Prevalecerían en esos países heterogeneidades de múltiples órdenes en las diversas estructuras (productivas, sociales, regionales, económicas y culturales) que yacen en el centro de los estilos de desarrollo según Pinto (1970; 1976).

Según los autores latinoamericanos, no es solo el hecho de que esas y otras estructuras son retrasadas, más bien que, a lo largo del tiempo, las limitaciones, privaciones, mutilaciones y el hecho del subdesarrollo acaban por deformar aún más las estructuras (productivas, ocupacionales, de distribución de renta y riqueza y la propia composición de clases sociales, junto con otros procesos) que habían sido forjadas diacrónicamente a lo largo de las limitaciones históricas puestas por la inserción subalternada de aquella escala nacional en el concierto de las relaciones con la dinámica mundial. 
El subdesarrollo entendido, no como fase o etapa, sino como ser, que coevoluciona en el tiempo con otro ser, el desarrollo. Ese fue el gran mérito del pensamiento latinoamericano, contribución que no fue bien entendida por los autores del Norte. De esta manera, hubo un paso decisivo en la interpretación de los caracteres distintivos del sistema de relaciones centro-periferia y la naturaleza peculiar de las vinculaciones establecidas con el exterior, a partir de los espacios subalternados.

A su vez, los seguidores de los pioneros latinoamericanos contribuyeron con análisis profundizados de la investigación de la naturaleza del capitalismo periférico, cuestionando los porqués de su no establecimiento en esos países: i) un núcleo endógeno de acumulación que se industrializa; ii) un patrón autónomo y sustentado de financiación y de crédito de largo del plazo; iii) un sistema de aprendizaje capaz de endogenizar el progreso técnico y la innovación; iv) un sistema de exigencia que pudiera constituir, a su vez, un sistema tributario no regresivo y penalizador del rentismo y del patrimonialismo, capaz de soportar con fondos públicos un Estado con la capacidad de formulación e implementación estratégica; v) una estructura de distribución de renta y riqueza capaz de realizar sus tareas sancionadas por proyectos democráticos y populares de encadenamiento de decisiones transformadoras del status quo vigente en cada ciclo histórico.

Señalaban que en América Latina persistían arritmias, asincronías e incompatibilidades entre, por lo menos, cinco estructuras: consumo, distribución de renta, propiedad, productividad y estructuras ocupacionales, que eran aún más agravadas por la decisiva presencia de las grandes corporaciones multinacionales en los principales enlaces de las cadenas productivas de mayor densidad tecnológica, configurando una estructura productiva bastante heterogénea y de baja calidad en la generación de empleo e innovación.

Precisamos retomar ese debate clásico del pensamiento crítico latinoamericano, buscando actualizarlo para un mundo cada vez más asiático; en el que casi todos los imperios seculares o milenarios volvieron a la escena del tablero geopolítico, resaltando la enorme complejidad en las relaciones centro-periferia.

Hoy hay un gran desafío que sería identificar y calificar las potencialidades, como también las ausencias, negligencias y limitaciones del pensamiento crítico histórico estructural latinoamericano que sean dignas de anotación para la formulación de investigaciones colectivas de alta complejidad. Un punto central sería cuestionar la forma en que el pensamiento crítico latinoamericano trató las escalas espaciales.

No es que el estructuralismo histórico latinoamericano no comprendiera la concepción de escalas espaciales, pero sí es necesario resaltar que estaban su- 
bentendidas, no totalmente expresas, más bien presupuestas o implícitas, en sus creativos análisis de la división internacional del trabajo. En la escala nacional se analizaron las estructuras y los agentes autóctonos, como si solo estuviesen ubicados e insertados en una moldura de encuadramiento circunscrito y estáticamente limitado. Estas y otras escalas (la subnacional, por ejemplo) no fueron concebidas como construcciones sociales conflictivas, relacionales, contestables, procesuales y contingentes.

Otra cuestión seria averiguar cuáles serían las particularidades del Estado latinoamericano, las coaliciones y fracciones de clase en su interior y sus específicas formas de reescalonamiento. Con seguridad, desde el punto de vista un tanto complejo en la escala mundial (sobre todo de su geopolítica y geocultura), ese pensamiento poco cuestionó cual sería la naturaleza de la escala nacional en un espacio nacional periférico, sin autonomía de decisiones, dependiente asociado, y con posición subordinada en el concierto de las relaciones y de las divisiones internacionales e interestatales. Al analizar solamente el núcleo versus la periferia, es decir, las formas unidireccionales de conexión de esta última en el espacio céntrico, el carácter dinámico y relacional de las vinculaciones endógenas-exógenas no ha sido tan analizado.

Seguramente dos de las limitaciones del estructuralismo histórico latinoamericano para entender el capitalismo actual serían: i) desarrollar una concepción alternativa de Estado, de conflictos sociopolíticos y de las relaciones centro-periferia en el siglo XXI; ii) desarrollar otra concepción de las escalas espaciales de los procesos sociales, construyendo un abordaje de multiescalaridad sistémica.

A pesar de la originalidad de sus reflexiones sobre la condición periférica, el estructuralismo histórico latinoamericano no logró recuperar y analizar adecuadamente la riqueza de la diversidad de sus trayectorias nacionales (con sus procesos específicos de acumulación, regulación, dominación, alienación y legitimación), sin incurrir en algún tipo de nacionalismo metodológico.

En verdad, sus principales autores siguieron padeciendo de cierto nacionalismo metodológico que exagera en las relaciones horizontales, descuidando las potentes relaciones verticales relacionales y de coevolución contradictoria. O sea, cada escala nacional se encuentra envuelta en complejas relaciones centro-periferia, redes económicas y políticas globales entre otras, que requieren análisis específicos.

Descuidaron, o poco consiguieron capturar, las dinámicas de la geometría variable de los enfoques del capitalismo, la multiplicidad de espacios nacionales y regionales y sus respectivas y peculiares capacidades de respuesta, ante la constante 
penetración y reconfiguración realizada por las redes y agentes institucionales y económicos multiescalares (Fernández, 2017).

En resumen, es necesario poner bajo sospecha la idea de la economía nacional como unidad analítica válida, ignorando las configuraciones socioespaciales en sentido más plural (Jessop, 2008). Superar el nacionalismo metodológico reedificador, para comprender, desde sus dinámicas internas, los comportamientos mundializados y la complejidad de las relaciones centro-periferia es el desafío de hoy, sobre todo para intentar capturar la complejidad escalar del capitalismo actual a partir de la periferia. No se pueden descuidar las determinaciones exógenas y coyunturalmente contextuales, que proviene de los Estados supranacionales imperiales hegemónicos, en un contexto mundial de inserción en sistemas interestatales en disputa según lo señala Fiori (2014).

El patrimonio del pensamiento crítico latinoamericano precisa ser renovado. Una de las tareas será incorporar el papel del poder, de las clases sociales y de la reiteración de las formas de dominación, del reescalonamiento estatal y de las diputas geoeconómicas y geopolíticas interestatales, a fin de analizar experiencias nacionales particulares.

\section{PARTICULARIDADES DEL CAPITALISMO PERIFÉRICO DE BRASIL EN EL PERIODO RECIENTE: REFLEXIONES INSPIRADAS EN EL PENSAMIENTO CRÍTICO LATINOAMERICANO}

Un listado de las especificidades del capitalismo en Brasil debe comenzar por la inusitada dotación de gigantescas fronteras interiores de valoración; por la precariedad de la constitución de clases sociales más dinámicas (marcado por el colonialismo portugués y por la esclavitud); la falta de compromiso de sus elites con el territorio y con el espacio nacional, la destitución de derechos y el desamparo a que están sometidas las clases subalternas, entre otras características estructurales.

Las preguntas claves que formulamos aquí a esta especie de capitalismo periférico, que no tenemos la pretensión de contestar en este trabajo, pero que sí nos ayudan a comparar el capitalismo político brasileño con otros, pasan por intentar entender: ¿Cuáles son las circunstancias y cuál la composición y la naturaleza de las alianzas que permitieron montar la máquina de desigualdades dotada de tal potencia y sofisticación? ¿Qué lleva a la persistencia en el funcionamiento de esta máquina de (re)producción de múltiples desigualdades y de preservación de estructuras socioeconómicas de explotación, expropiación y marginalización? ¿Por qué no se arma un sistema de fuerzas productivas vigoroso, con amplia capacidad 
de generación y distribución de riqueza material? ¿Cuáles son los bloqueos que impiden engendrar impulsos articuladores del conjunto de la actividad económica dotados de coherencia sistémica de toda la estructura económica y productiva o una división-articulación socioterritorial de la dinámica del trabajo?

En este contexto, se vuelve importante interrogarse sobre las especificidades de nuestro sistema económico y social que dio soporte a un complejo sistema mercantil, y de esta manera cuestionar sus alianzas e instrumentos de poder, sus mecanismos de actuación, sus relaciones geopolíticas y geoeconómicas, sus articulaciones con el régimen de acumulación financiada y su enganche cíclico subordinado a las olas de liquidez internacional.

En este contexto, es importante cuestionar sobre la naturaleza y las limitaciones a que están sometidos tanto en el núcleo de acumulación (NA) como el núcleo de implicación estatal (NIE) brasileños (Fernández, 2017).

En Brasil, las duras marcas del retraso estructural, impresas de forma perenne en el territorio y en las relaciones sociales, están fundadas en una historia de expansión a lo largo de la amplia plataforma territorial, de extensión continental, en las que yacen las clases sociales con bajo potencial transformador, frágilmente constituidas y fundadas. Arriba, clases fundadas y arraigadas en formas mercantiles patrimonialistas y financieras, usureras y rentistas, sin compromiso con el pueblo y la nación. Abajo, clases destituidas de derechos y de propiedad.

Al analizar la dinámica de acción de las facciones diferenciadas de las clases sociales, se evidencia la precariedad de la constitución de sujetos sociopolíticos portadores de decisiones transformadoras, lo que pone barreras estructurales a la construcción politizada de procesos de desarrollo. Lo que se reafirma, recurrentemente, es la amplitud y el poder de las estructuras políticas conservadoras y reaccionarias, con incapacidad congénita para dar universalidad a la ciudadanía, a los derechos sociales y promover fuerzas (re)productivas con organizaciones capitalistas más modernas.

Hay una especie de insuficiencia dinámica estructural, ante los enormes desafíos de construcción de las bases materiales requeridas para las tareas transformadoras de busca de superación del subdesarrollo (Brandão, 2018).

De esta manera, la historia brasileña puede ser sintetizada en movimientos en que todas las heterogeneidades estructurales y las diversidades productivas, urbanas, sociales y ambientales estuvieron subordinadas a la lógica económica de la valoración fácil y rápida, es decir, de naturaleza inmediatista, rentista y patrimonialista. 
En resumen, los grandes ciclos, en una sencilla y poco rigurosa periodización de la historia brasileña, deben contemplar por lo menos los períodos de: 1500 a 1820, colonia de Portugal; 1820 a 1889, país independiente-imperio; 1889 a 1929(33), república vieja; 1933 a 1963, industrialización desarrollista y diversificación social; 1964 a 1982, golpe militar-empresarial, autoritarismo y endeudamiento externo; después de 1983, diversas oleadas de ajustes, austeridades y neoliberalización.

En la larga duración histórica de quinientos años, Brasil pasa de mera plataforma de factorías, haciendas y unidades aisladas de negocios mercantiles y verdadero archipiélago de núcleos monocultores y primario exportadores, centrífugos y exogeneizados (Furtado, 1970), que tiene toda su lógica de funcionamiento sometida a los designios de los mercados externos y a la acumulación primitiva y a la explotación del centro, a estructurar en su heterogéneo y continental territorio una de las diez mayores y complejas economías nacionales urbano-industriales capitalistas del mundo.

El sistema económico nacional configurado en el siglo XX alcanzó un elevado grado de integración comercial y productiva, al dotarse de una red matricial de relaciones intra e inter-ramos económicos, que se distribuyó desigualmente por todo el país y, aunque con alta concentración espacial, fue virtuosa en la articulación de todas las economías regionales en una complementariedad expansiva, que conformaba un todo que no crecía en conjunto, sino con fuertes asimetrías y arritmias entre sus partes cohesionadas. Se consolidó un complejo esquena de relaciones centro-periferia entre sus diversas regiones, anclado en una larga trayectoria de nexos interregionales articuladores, que solidarizaron, por la vía del mercado, las partes del país, lo que hizo que los variados espacios regionales confluyesen sus proyectos y coaliciones de expansión alrededor de una convención desarrollista durable por medio siglo (1930 a 1980).

A partir de la segunda mitad de los años 1950 el país viviría profundas transformaciones económicas, culturales, sociales y políticas, todas sometidas al carácter de modernización conservadora que condujo tales cambios estructurales. La modernización de tal naturaleza agudizaría aún más los elementos históricos de heterogeneidad estructural (productiva, social y espacial), marcas de la variedad periférica de capitalismo.

El golpe militar de 1964 representaría la victoria definitiva ante la potencial vía alternativa, democrática y con inclusión social, que avanzaba en el país. Cualquier periodización sobre nuestra historia y sus especificidades sociales, económicas y políticas debe realizar un corte temporal en 1964. Para el estudio de la dinámica de 
nuestra sociedad es necesario recordar ciertas determinaciones y condicionantes impuestos en el período 1964-1985.

La destrucción del Estado democrático de derecho, perpetrada por el golpe de 1964, acabó por devastar estructuralmente la política y la formación de clases sociales en Brasil. El régimen autoritario de veintiún años desmanteló la esfera política, el espacio público, las bases democráticas, destituyendo derechos y las fuerzas populares en los centros de decisión.

Un aparato de gestión pública tecnicista, autoritario y con alta centralización de decisiones se ha erguido durante esta modernización despótica conservadora, que desmanteló y reorganizó administrativa y burocráticamente el Estado.

La industrialización avanzó, arrastrando e incentivando el conjunto de las actividades económicas terciarias, agropecuarias y de soporte infraestructural. Se procesaron transformaciones materiales amplias en el NA (igual al de la segunda revolución industrial), pero no fueron acompañadas de mayor accesibilidad para la mayoría de la población a la propiedad, a la tierra rural o urbana, a la educación y a la salud de calidad, a la vivienda, a los servicios urbanos, a la inserción formal en el mercado laboral y en la seguridad social; es decir, la mayoría quedo sin derechos a la economía urbana moderna. Sin embargo, se avanzó en la construcción de un espacio nacional, erigido bajo nuevo modelo de acumulación, vía profundización de mecanismos de políticas públicas protectores y controladores de reproducción ampliada de diversas facciones burguesas, lo que consolidó una capacidad de dar coherencia a la valoración de un muy amplio frente de capitales fragmentarios -bastante asimétricos, según los cortes sectoriales, regionales, de porte- aunque ahora integrados productivamente.

El nuevo modelo agrícola que se erige después de 1965, con la institucionalización del Sistema Nacional de Crédito Rural, que promovió la industrialización de la agricultura, profundizó la modernización conservadora del agro y ejerció presión en las relaciones de producción y de propiedad, determinando masivos movimientos de expulsión de la zona rural.

En el plan económico, se han definido articulaciones a partir del epicentro del aparato productivo nacional, localizado en el eje Río-São Paulo, estructurando un complejo industrial mercantil financiero. En la cuarta parte del siglo XX, la acción estatal, sobre todo en la periferia nacional, reforzó su papel de inversionista directo y estructurante del territorio nacional. La implementación de un pesado bloque de inversiones, a partir del II Plan Nacional de Desarrollo (1974/76), le ofreció infraestructura básica y avanzó inversiones directas de los sistemas productivos estatales 
y las industrias de insumos básicos y de bienes de capital (petroquímica, energía y siderurgia), articulando las bases económicas regionales en una fuga expansiva ramificada sectorialmente por el territorio.

En el plan social, el crecimiento económico generó capacidad, limitada territorialmente, pero potente, de absorción en estructuras ocupacionales formales para ciertos niveles de la población, que han sido entrañadas por dinámicas de movilidad intergeneracional e interespacial, con la expansión y diversificación de los estratos urbanos medios y metropolitanos en cada Estado de la federación. Otros niveles, acabaron relegadas a otras órbitas suburbanas, marcadas por la marginación, desafiliación y desclasificación. Se consolidó un régimen de crecimiento económico rápido, y por los caminos de menor resistencia, que legitimó un estilo perverso de convivencia social, depredación de recursos naturales, valores culturales y espacios geográficos. En suma, en términos nacionales y, sobre todo durante los cincuenta años gloriosos de Brasil (1933/82), se consolidó una sociedad de masas compleja, dispersa y amorfa.

En el plano político, frente a esa masa informe que se dispuso diferenciadamente por todo el territorio nacional, se solidificó incontestable la hegemonía del bloque en el poder de las cumbres políticas mercantiles- territoriales-rentistas que dominan Brasil. Con sus marcas históricas de imposición no democrática, por la vía dictatorial, ancladas en los privilegios de la valorización garantizados por el Estado, en las órbitas extensivas de la circulación de los capitales, en el control inquebrantable de la propiedad (rural y urbana) agraria e inmobiliaria y en el uso geopolítico privatizado del territorio.

Si bien nunca fueron vencidos, se reposicionaron los caudillismos, regionalismos y localismos oligárquicos y conservadores y la profusión de narrativas escalares y espaciales de las retóricas parroquialistas y reaccionarias, muchas antipopulares y antinacionales.

Brasil ha levantado, en un proceso de larga duración, una sociedad urbana de masas compleja, sin urbanidad, fruto de la producción de espacios precarizados e ilegales, con negación del derecho a la ciudad para la mayoría, y bajo el control férreo de las élites agrarias, inmobiliarias y rentistas urbanas y rurales, poco sometidos a la disciplina de los poderes públicos y los designios colectivos.

Brasil ha montado una economía urbana moderna, con sofisticada estructura reproductiva diferenciada (compuesta por variadas fracciones de clases sociales), estructura productiva diversificada (industrial, agropecuaria y terciaria) y heterogeneidades estructurales (sociales, regionales, rurales y culturales) muy marcadas. 
Los complejos procesos, de largo recorrido y de naturaleza contradictoria, dejaron huellas de la fuga hacia adelante, del dinamismo económico de los efectos de multiplicación y aceleración del ingreso y de la riqueza, pero también quedaron las marcas de la interdicción estructural y de los bloqueos coyunturales recurrentes de las reformas sociales, de la distribución de ingresos y de la habilitación por la propiedad y por el acceso a los derechos, para la mayoría de la sociedad.

El proceso expansivo de medio siglo de inserción con crecimiento en el contexto internacional de la posguerra fue abruptamente interrumpido en 1983 tras la crisis de las deudas latinoamericanas. Con la crisis de liquidez, la deuda y las insolvencias generalizadas, no se permitió a los países periféricos honrar sus compromisos con los servicios de la deuda externa.

A partir de ahí tuvimos pequeños ciclos inconsistentes de crecimiento, el desposeimiento del patrimonio público (y su usurpación por el sector privado), que había sido construido en medio siglo de luchas y crecimiento; la crítica casi generalizada al Estado interventor; y, en suma, la reacomodación y cristalización de los viejos compromisos del amplio arco de alianzas conservadoras que dominan el núcleo del poder en Brasil.

A fines del siglo XX estas características macroestructurales históricas se exacerbaron en razón de las opciones neoliberales de conducción de la política económica realizadas. El Estado perdió poder de coordinación estructurante para orientar y promover frentes de expansión atractivos, haciendo cada día más difícil acomodar y hacer converger tantos, grandes y dispersos intereses. Se consolidó una enorme pérdida de capacidad de concatenación por parte del Estado y, en consecuencia, de inducción de la inversión privada. Sucedió una reespecialización y una remercantilización, ya que Brasil durante los años 1990, profundizó aún más sus ventajas competitivas estáticas y absolutas históricas en los segmentos estandarizados y de procesamiento continuo de recursos minerales, forestales, energéticos, agrícolas y ganaderos, como la producción del mineral de hierro, la siderurgia y el aluminio (básicamente insumos metálicos semiacabados), petróleo y petroquímica, celulosa y papel, alimentos industrializados (granos, jugo de naranja, carnes) y textiles estandarizados. Algunos intentos de discusión o implementación de políticas industriales se realizaron, pero sin ninguna capacidad de creación de nodalidad del Estado (Fernández y García, 2013) frente a los atomizantes y parroquiales intereses empresariales.

Se evidencia, entonces, un Estado primero de naturaleza burocrático-autoritario, del período militar, después, gerencialista y privatista, que, aunque logró realizar la 
complementación de la segunda revolución industrial, esta se dio sin la constitución de aglomeración capitalista para constituir grandes grupos empresariales nacionales, sin estándares de financiación a largo plazo y sin sistema de aprendizaje e innovación. Por lo tanto, sin un Estado con capacidad nodal para disciplinar a las fuerzas privadas y conducirlas en una estrategia competitiva sistémica.

En lo que se refiere al plano político, las fuerzas sociales y políticas de la redemocratización, que habían impuesto importantes avances durante el proceso de elaboración de la Constitución de 1988, no lograron hacer frente al proceso avasallador de la verdadera revolución conservadora (con el implante de la razón neoliberal) que se tomó al país.

La década perdida, de 1980, seguida de la desperdiciada, de 1990, fueron caracterizadas por brotes sectoriales, incoherentes, inestables y focalizados de crecimiento económico en restringidos puntos en cada una de las macrorregiones brasileñas. La pérdida generalizada de dinamismo económico y la ampliación de los desniveles socioeconómicos entre sus regiones fueron determinados por el ambiente macroeconómico internacional, las opciones equivocadas de política económica y la pérdida de la calidad sistémica y orgánica de la actuación del Estado, lo que resultó en arrítmicas inversiones públicas y privadas y determinaron importantes transformaciones en las relaciones entre las regiones brasileñas. Estas fueron impactadas selectivamente y sectorialmente en sus estructuras socioeconómicas y urbano-regionales. En los tres niveles de gobierno de la federación ha sido muy diversa la sensibilidad de cada región a los procesos de apertura, a los determinantes microeconómicos de la reorganización empresarial, al deterioro de la infraestructura económica y a la desestructuración del sector público (Siqueira, 2015).

Desde la crisis de la deuda (1983), pasando por el frente posrégimen militar, la Nueva República (1985/1990), hasta el intento fracasado del gobierno Collor de Mello (1990-1992), una reorganización de los liderazgos políticos se articuló para poner fin a la llamada era Vargas (1930/80) y resolver la crisis de hegemonía. La elección de Fernando Henrique Cardoso involucró algunas condiciones económicas, políticas y fiscales favorables que posibilitaron el Roll-Back de la experiencia de industrialización y el Estado coordinador. De hecho, el ataque a la era Vargas, junto con el plan de estabilización, fue la prioridad del primer mandato de Cardoso. Como parte del proyecto de romper algunos de los ejes legales del Estado nacional-desarrollista, parte de los cuales fueron incluidos en la Constitución de 1988 (Sallum, 1999), se destaca la reorganización institucional de las relaciones entre el Estado y el mercado, expresado por el fin de la discriminación constitucional en relación con la empresa 
de capital extranjero y la transferencia a la Unión del monopolio de la explotación, refinería y transporte de petróleo y gas, lo que antes había sido de Petrobrás.

A pesar de sus diferencias contextuales, desde 1995, el Roll-Back se manifestó en sus formas clásicas: un ataque a las estructuras desarrollistas heredadas, asociado a la desregulación primitiva de los mercados. Este ataque se basaba en la administración macroeconómica monetarista, en la desregulación dogmática y en la privatización (Peck, 2010). En Brasil, esto se manifestó en los intereses altos, apertura comercial ampliada, ajuste fiscal progresivo, cambio sobrevalorado y rechazo de la política industrial, para aumentar la competencia y evitar las distorsiones promovidas por la intervención del Estado desarrollista de la era Vargas.

Pese el ataque predatorio al federalismo y a los elementos de derechos y ciudadanía de la Constitución de 1988, las fuerzas neoliberales no consiguieron eliminar todos sus rasgos desarrollistas. Tampoco logró imponer un neoliberalismo puro, a pesar del predominio de los fundamentalistas de mercado en el equipo económico. Esto se debe a la resistencia de la sociedad y a la necesidad del neoliberalismo de convivir con formas extramercado. En este sentido, es urgente investigar concretamente, en variados contextos georregulatorios, nuevas formas de desarrollo desigual y lo que Harvey (2014) denomina nuevas lógicas de formación, propagación y gestión de crisis durante estos años.

América Latina y Brasil soportaron profundas crisis políticas y económicas, en ambiente de bajo crecimiento y en contexto internacional de amplias reorganizaciones sistémicas, nacionalistas, interterritoriales e interempresariales. El carácter del régimen de crecimiento impuesto al continente, de extracción y explotación de los recursos naturales minerales, agrícolas y energéticos (renovables y no renovables, como reservas de petróleo y los depósitos minerales no energéticos) restablece las problemáticas estructurales de nuestra experiencia histórica periférica, de congénita insuficiencia de agentes dinámicos y estructurantes dotados de liderazgo y de vigor para buscar penetración e inserción internacional más activa y dinámica en la mutante geopolítica y geoeconomía en la escala mundial.

En Brasil, además del avance del poder del agronegocio, de la extracción mineral y sus respectivas infraestructuras de logística y energía se colocan en el centro de esta agenda neoconservadora la cuestión del petróleo de la capa del presal. Las discusiones del grado de autonomía de decisión de ese espacio nacional, que opta, por ejemplo, por la especialización regresiva -con concentración de la estructura productiva, ya bastante heterogénea, en la oferta de commodities de baja elaboración y en la explotación de recursos naturales, estrategias de ajuste pasivas y defensivas, 
basadas en competitividad espuria, no dirigidas para el aprendizaje-son reveladoras de la limitación o ausencia de proyectos de desarrollo nacional de países como Brasil.

\section{EL PROCESO DE NEOLIBERALIZACIÓN Y SU CARÁCTER CÍCLICO: PENSANDO SU SINGULARIDAD EN EL BRASIL CONTEMPORÁNEO}

Una muy promisoria literatura se desarrolló en el inicio del presente siglo, buscaba construir un marco teórico de investigaciones comparadas de las experiencias concretas de procesos específicos de neoliberalización.

Dentro de ese marco teórico, los autores de las VC (Brenner, Peck y Theodore, 2011) posibilitaron una importante contribución al caracterizar la neoliberalización como un proceso siempre incompleto, contradictorio, contestado y complejo de experimentaciones socio-político-espaciales. Elaboraron una interpretación en la que este debe ser tratado por su naturaleza fungible, híbrida, maleable, dependiente de la trayectoria pasada y abierto en relación con el futuro, que se desarrolla e impregna en cada ambiente y se encuentra en permanente transformación de los contornos institucionales que van siendo rediseñados en cada tiempo coyuntural. Nunca es unidireccional, pero siempre es adherente y adaptable a contextos variados.

Muy distante de esta narrativa liberal conservadora, la realidad concreta es que promover el proceso de neoliberalización requiere una gran y potente intervención, conjuntamente con cambios amplios y profunda participación del Estado. Ese proceso se presenta en cuanto surge una verdadera ola de asalto y reapropiación privada de los fondos públicos para la redistribución dentro del bloque en el poder, apertura de nuevas frentes de valoraciones, privatización de los servicios públicos etcétera. Generalmente, toma la forma de marcada re regulación de las tres mercaderías ficticias (trabajo, dinero y tierra) según Polanyi (1944), todo para hacer avanzar la conformación de la sociedad a las fuerzas de mercado. O sea, lo cierto es que esas fuerzas mercantiles no llegan por el curso natural de los acontecimientos, como está inscrito en el origen del credo liberal. Requieren amplia reorganización de potencias estatales para que sean engendradas autoritariamente. Es importante resaltar que los valores democráticos no hacen parte de sus atributos, o mejor, la antidemocracia o la ademocracia es su marca creciente del modo neofascista de neoliberalización.

Brenner, Peck y Theodore (2011) propusieron una periodización muy interesante, distinguiendo dos momentos en los procesos de neoliberalización. De esta manera, las formas neoliberalizadoras ocurrirían en dos muy distintos rounds de reestructuración regulatoria. En el primero, que denominan de Roll-Back, o sea, 
de ataque ofensivo, en que se promueve el desmantelamiento de las instituciones, desorganizando centros de poder, espacios burocráticos y se procura, por diversos dispositivos, disciplinar sujetos colectivos. En un segundo round, que se llama RollOut, de re-regulación, surge un reatrincheramiento, enfrentando modos de gobernanza diversos erigidos anteriormente y se realiza una incursión e implementación regulatoria que garantiza modos de conformación a los designios de los mercados (Peck, 2010). Furtado (1961) había presentado ideas semejantes al discutir cómo se desarrollan fórmulas sociopolíticas para imponer racionalidades instrumentales prefiguradas por el mercado.

Ese debate es central para profundizar en las investigaciones de cómo los procesos neoliberalizantes se extienden y se arraigan, en rondas cíclicas, plásticas, resilientes y contingentes, espacialmente especificadas, sea en un primer momento más destructivo de desmonte, sea en un momento más proactivo de reglamentación, remontaje y reatrincheramiento.

Intentamos en este ensayo dialogar con esa literatura del Norte, a partir de la periferia subdesarrollada con sus acúmulos de retrasos en sus bases materiales e institucionales, con menguadas arenas de contestación, baja fuerza de organización democrático-popular, frágil democracia (o democracia de bajo impacto) e instituciones autoritarias sometidas a la potencia de las redes económicas y políticas.

En ese contexto, sería importante procurar hacer dialogar el pensamiento crítico latinoamericano con los abordajes de las VC, para tratar su vertiente periférica y subdesarrollada, investigando casos concretos ${ }^{1}$. Analizaremos aquí la situación reciente brasileña.

En los últimos 23 años, de 1995 a 2018, Brasil sufrió tres oleadas de neoliberalización. Así, tuvimos los gobiernos de Fernando Henrique Cardoso -FHC- (1995/2002); el lulismo (2003/2015) y el régimen de mercado autorregulado de Temer (2016/2018), que parece haber abierto espacio para su radicalización en el periodo posterior a 2019. Esas oleadas echan mano de dispositivos, mecanismos e instrumentos bastante diferenciados de experimentaciones reguladoras, con variadas repercusiones, en las tres mercancías ficticias: tierra, dinero y trabajo.

Durante los conservadores años 1990, marcados por el Consenso de Washington, tuvimos dos gobiernos FHC (1995/2002), en que se realizaron típicas estrategias de Roll-Back, de ataque ofensivo y desmantelamiento de instituciones públicas que regulaban el mercado, liberando sus fuerzas para actuar más libremente. Fue un momento de privatizaciones, internacionalización de la economía, destrucción

Ese es un proyecto de investigación que será abordado a futuro. 
de puestos de trabajo, de derechos y de garantía, con vigorosa represión a los movimientos sociales.

De esta manera, las reformas adoptadas en el mandato de FHC fueron en el sentido de perfeccionar para intensificar la neoliberalización, lo que incluía simultáneamente el desmantelamiento y la creación de nuevas instituciones y la reestructuración del Estado (Peck, 2010).

El periodo fue marcado también por el auge en la regulación económica tecnocrática, caracterizado por el aislamiento del Ministerio de Hacienda y del Banco Central. El blindaje del equipo económico funcionó como una autonomía inmersa con señal intercambiada, siendo que la red de decisiones e informaciones conectó el Estado al mercado financiero (Couto y Abrucio, 2003). En ese sentido, el poder de una burocracia educada en centros conservadores extranjeros ayudó a ilustrar las relaciones entre el neoliberalismo y la internacionalización del Estado (Peck, 2010).

El predominio de la agenda conservadora permitió la institucionalización de un régimen de políticas que, sin embargo, acabó rehén del fiscalismo. Las divisiones en la coalición política que sostuvieron el gobierno se intensificaron tras el débil crecimiento y el fallo en el modelo regulatorio (principalmente en el sector eléctrico) y argumentaron que el gobierno no tenía un proyecto de Estado definido tras el ataque a la era Vargas (Couto y Abrucio, 2003).

En el Lulismo (2003/2015), a pesar de la potencia de las políticas sociales implementadas, la neoliberalización persistió, sobre todo en razón de la política macroeconómica conservadora.

Una reforma del sistema de pensiones draconiana fue realizada en 2003. Alianzas con algunas de las fuerzas más retrógradas y conservadoras de Brasil, con ampliación de la protección al rentismo y al patrimonialismo; el no enfrentamiento de las cuestiones relativas a las tierras rurales y urbanas, entre muchas otras políticas de tipo neoliberal. Por todo eso, se puede denominar el período de los gobiernos Lula y Dilma como una especie de ola intermedia en el conjunto de las tres oleadas de neoliberalización que experimentamos hacia finales del siglo veinte y primeras décadas del veintiuno.

Durante los gobiernos de Lula y Dilma las reestructuraciones regulatorias de gran alcance fueron implementadas en una ola de Roll-Out, de regulación, entrante, enfrentando modos de gobernanza anteriores y creando refugios de defensa que mezclaron sumisión a los mercados con la defensa de algunos derechos sociales. 
Algunos trabajos recientes han discutido si hubo una reversión de la trayectoria del neoliberalismo a lo largo del gobierno de Lula o si se produjo una mera continuidad de políticas anteriores (Pinto, 2010), o si hubo cambios significativos, aunque en un contexto neoliberal con desplazamientos en el bloque en el poder (Boito Jr., 2018).

Tras el impeachment de Dilma, los procesos neoliberalizantes se extienden y se arraigan, en una oleada más que libera al molino satánico (Polanyi, 1944) del mercado para funcionar sin restricciones, en un momento de deconstrucción institucional y ataque a la democracia.

Lo que es impresionante es cómo en poco más de 20 años, Brasil demostró la fragilidad de su joven experiencia democrática: tres oleadas de neoliberalización bastante distintas y contradictorias, un Roll-Back, un Roll-Out y un nuevo Roll-Back todavía más radical que el primero, con tendencias de emersión en un neoliberalismo de carácter neofascista activo.

Con matices que podrían distinguirse entre las tres oleadas de neoliberalización de los últimos dos decenios, en todas ellas persistió la redistribución a favor de las rentas del capital, en detrimento de las rentas del trabajo. Incluso en la ronda RollOut del lulismo, que promovió una importante distribución personal de la renta, con aumento de la homogeneidad social, la llamada distribución funcional de la renta no cambió mucho a favor de la masa de salarios en relación con la masa de ganancias.

Los reinos de las finanzas, del agronegocio y de la internacionalización abierta ganan terreno. Por otro lado, la profundización de la crisis, la violencia multidimensional, los graves problemas urbanos, demuestran la fragilidad del mercado laboral brasileño, que crea nuevos puestos en cada ciclo y luego los destruye rápidamente. Además, es creciente el endeudamiento familiar de los más pobres, en un momento de aumento del desempleo, recesión y retirada de sus derechos duramente conquistados.

La coyuntura actual es de exacerbación de los viejos y nuevos conflictos urbanometropolitano y agrarios, la fragmentación de una sociedad moderna de masas, con la mayor complejidad de las disputas de las variadas subfacciones de clase, con enorme compartimentalización y despolitización, lo que hace ascender nuevas dinámicas de los movimientos sociales en sus luchas por la democracia y la justicia.

Históricamente, incluso con la modernización conservadora urbanizada, jamás se consolidaron legitimación y fuerza política suficientes para romper el obstáculo a la implementación de políticas sociales y a la habilitación por la educación y la propiedad a gran escala. 


\section{CONCLUSIONES}

Al contrario del mainstream de las ciencias sociales y su visión conservadora que propugna un rumbo preestablecido, un alineamiento hacia una composición uniforme de capitalismo con estructuras semejantes, la realidad concreta e histórica demuestra que hay heterogeneidad en las experiencias nacionales y regionales. El sistema capitalista es por naturaleza polimórfico; sigue diversificadas trayectorias y vías; asume y altera diferentes configuraciones multidimensionales, ya que está sujeto a constantes movimientos contradictorios en sus estructuras y dinámicas, con pugnas y coerciones reiteradas entre distintos estilos de desarrollo en proceso conflictivo, contingente y abierto. Hay competición permanente de Estados territoriales y experiencias diferenciadas de desarrollo, con capacidades heterogéneas de respuestas en el interior de la complejidad capitalista. De ahí la necesidad del estudio de sus particularidades y de su modo diverso de organización de la vida social en cada contexto histórico, institucional y geográfico.

Contra la visión de la existencia de una monomorfología en el capitalismo, se desarrollaron los enfoques de las diversidades y variedades de capitalismos. Originalmente, tales interpretaciones procuraron aprehender la diversidad capitalista, a través de la comparación institucional, sobre todo de las economías nacionales (cerradas) en el contexto del centro, del Norte. A pesar de sus contribuciones, estos enfoques presentan muchas limitaciones.

El enfoque VC no enfrenta en sus análisis las contradicciones, complejidades, la flexibilidad molecular de la acumulación en red, los conflictos, las disputas de poder, el papel central del Estado, la competencia interestatal, las relaciones centroperiferia, la naturaleza específica del subdesarrollo, entre otras situaciones.

A menudo, deteniendo una visión armoniosa de los procesos sociales históricos, propone modelos y recetas abstractas en las que se descuidan las determinaciones reales y concretas en el concierto de una división internacional del trabajo jerarquizada y compleja. En realidad, la exacerbación de la coerción de competencia intercapitalista y los intereses territoriales, ha promovido una colosal aceleración de la intensificación de la explotación laboral, la expropiación de bienes y recursos comunes, el aumento de la inseguridad y de la individualización, con el desmonte de las regularidades y de los compromisos de clase con negociados típicos del consenso del momento anterior.

En los principales países de América Latina, las históricas problemáticas de la desindustrialización, reprimarización, neoextractivismo, entrega del patrimonio común o público a la iniciativa privada foránea, la expansión de los enclaves de 
explotación de recursos naturales, la especialización regresiva en bienes primarios, entre otros fenómenos, están de vuelta y se reactualizan en la vieja narrativa de la necesidad de modernizar esos países, que ha sido impuesta por la presente oleada de neoliberalización que asola actualmente todo el continente desde el año 2016. De esta manera, en los últimos 23 años, de 1995 a 2018, Brasil fue sometido a tres muy distintas olas de reestructuración regulatoria, discutidas en este artículo. Fueron los momentos de imponer activamente las fuerzas de mercado que corresponden a los gobiernos FHC (1995/2002); Lula-Dilma (2003/2015) y el del golpe jurídico-mediáticoparlamentario (2016-2018).

Sostenemos que la profundización de los estudios de las especificidades de los capitalismos subdesarrollados, dependientes y periféricos, pueden arrojar luz no solo para el debate de la situación de la mayoría de las poblaciones del planeta, como para demostrar la otra cara del desarrollo del capitalismo del centro.

\section{BIBLIOGRAFÍA}

Boito Jr., Armando. (2018). Reforma e crise política no Brasil: os conflitos de classe nos governos do PT. Campinas: Editora da Unicamp, 336 p.

Boyer, Robert. (2005). How and why capitalisms differ. Köln: Max-Planck-Institut für Gesellschaftsforschung. (MPIFG Discussion Paper, 05/4).

Brandão, Carlos A. (Org.). (2018). Teorias e políticas do desenvolvimento latino-americano. Río de Janeiro: Centro Celso Furtado/Contraponto, 312 p.

Brenner, Neil; Peck, Jamie y Theodore, Nik. (2011). ¿Y después de la neoliberalización? Estrategias metodológicas para la investigación de las transformaciones regulatorias contemporáneas. En: Urban, n. ${ }^{\circ}$ 1, p. 21-40.

Coates, David. (Ed.). (2005). Varieties of capitalism, varieties of approaches. Londres: Palgrave, $300 \mathrm{p}$.

Couto, Cláudio y Abrúcio, Fernando. (2003). O segundo governo FHC: coalizões, agendas e instituições. En: Tempo Social, São Paulo, vol.15, n. ${ }^{2}$ 2, p. 269-301.

Fajnzylber, Fernando. (1983). La industrialización trunca de América Latina. Ciudad de México: Nueva Imagen, 416p.

Fernández, Víctor R. (2017). La trilogía del erizo-zorro: redes globales, trayectorias nacionales y dinámicas regionales desde la periferia. Santa Fe, Anthropos/UNL, 397 p.

Fernández, Víctor R. y García Puente, María Jimena. (2013). Estado, producción y desarrollo. Las capacidades nodales en una perspectiva latinoamericana. En: Revista Estado y Políticas Públicas, n. ${ }^{\circ}$ 1, p. 19-46.

Fiori, José L. (2014). História, estratégia e desenvolvimento. São Paulo: Boitempo, 366 p. 
Furtado, Celso (1961). Desenvolvimento e subdesenvolvimento, Río de Janeiro: Fundo de Cultura, $274 \mathrm{p}$.

Furtado, Celso (1970). Formação econômica da América Latina. Río de Janeiro: Nacional.

Hall, Peter y Soskice, David. (Eds.). (2001). Varieties of capitalism: the institutional foundations of comparative advantage. Oxford: Oxford University Press, $540 \mathrm{p}$.

Harvey, David. (2014). Diecisiete contradicciones y el fin del capitalismo. Quito: IAEN, 296 p.

Hollingsworth, J. Rogers y Boyer, Robert. (Eds.). (1997). Contemporary capitalism: the embeddedness of institutions. Cambridge: Cambridge University Press, 492 p.

Jessop, Bob. (2008). State power: a strategic-relational approach. Cambridge, Polity Press, 314 p.

Peck, Jamie. (2010). Constructions of neoliberal reason. Oxford: Oxford University Press, 301 p.

Peck, Jamie y Theodore, Nik. (2007). Variegated capitalism. En: Progress in Human Geography, vol. 31, n. ${ }^{\circ}$, p. $731-772$.

Pinto, Aníbal. (1970). Naturaleza e implicaciones de la "heterogeneidad estructural" de la América Latina. En: El Trimestre Económico, vol. 37, n. ${ }^{\circ}$ 145-1, p. 83-100.

Pinto, Aníbal. (1976). Notas sobre los estilos de desarrollo en América Latina, Revista de la Cepal, n. ${ }^{\circ}$ 1, p. 73-93.

Pinto, Eduardo C. (2010). Bloco no poder e Governo Lula: grupos econômicos, política econômica e novo eixo sino-americano. Tesis para optar al título de Doctor en Economía. Doctorado en Economía, UFRJ, Río de Janeiro, 455 p.

Polanyi, Karl. (1944). La gran transformación: crítica del liberalismo económico. Buenos Aires: Quipu Editorial, 474 p.

Prebisch, Raúl. (1949). El desarrollo económico de la América Latina y algunos de sus principales problemas. Santiago de Chile: Cepal, 64 p.

Prebisch, Raúl. (1981). Capitalismo periférico, crisis y transformación. Ciudad de México: Fondo de Cultura Económica, 345 p.

Sallum Jr., Basílio. (1999). O Brasil sob Cardoso: neo-liberalismo e desenvolvimentismo. En: Tempo Social, vol. 11, n. ${ }^{\circ}$ 2, p. 23-47.

Siqueira, Hipólita. (2015). Novo-desenvolvimentismo e dinâmica regional recente no Brasil (2004/2013). En: EURE, vol. 41, n. ${ }^{\circ} 122$, p. 261-277.

Tavares, María C. (1981). Problemas de industrialización avanzada en capitalismos tardíos y periféricos. En: Economía de América Latina, n. ${ }^{\circ}$, p. 21-42. 